ICEM05 / DECOM05

Spent Fuel, Fissile, Transuranic and High-Level Waste Management

Donald A. Kalinich

Sandia National Laboratories

702-295-5316 (ph)

702-295-3123 (fax)

Donald_Kalinich@ymp.gov

\title{
BUILDING AND RUNNING THE YUCCA MOUNTAIN TOTAL SYSTEM PERFORMANCE MODEL IN A QUALITY ENVIRONMENT
}

\author{
Donald A. Kalinich, Sandia National Laboratories \\ Kearn P. Lee, Framatome ANP \\ Jerry A. McNeish, Bechtel SAIC, LLC
}

A Total System Performance Assessment (TSPA) model has been developed to support the Safety Analysis Report (SAR) for the Yucca Mountain High-Level Waste Repository. The TSPA model forecasts repository performance over a 20,000 -year simulation period. It has a high degree of complexity due to the complexity of its underlying process and abstraction models. This is reflected in the size of the model (a 27,000 element GoldSim file), its use of dynamic-linked libraries (14 DLLs), the number and size of its input files (659 files totaling 4.7 $\mathrm{GB}$ ), and the number of model input parameters (2541 input database entries).

TSPA model development and subsequent simulations with the final version of the model were performed to a set of Quality Assurance (QA) procedures. Due to the complexity of the model, comments on previous TSPAs, and the number of analysts involved (22 analysts in seven cities across four time zones), additional controls for the entire life-cycle of the TSPA model, including management, physical, model change, and input controls were developed and documented. These controls did not replace the QA procedures, rather they provided guidance for implementing the requirements of the QA procedures with the specific intent of ensuring that the model development process and the simulations performed with the final version of the model had sufficient checking, traceability, and transparency.

Management controls were developed to ensure that only management-approved changes were implemented into the TSPA model and that only management-approved model runs were performed.

Physical controls were developed to track the use of prototype software and preliminary input files, and to ensure that only qualified software and inputs were used in the final version of the TSPA model. In addition, a system was developed to name, file, and track development versions of the TSPA model as well as simulations performed with the final version of the model. 
Model change controls were developed to ensure that model changes were adequately checked and that sufficient objective evidence of the changes and their checking was produced. Changes to the model were documented by a conceptual description of the changes and an item-by-item checklist of the changes. The TSPA modeling software (GoldSim) was modified to include a versioning feature that allowed changes between model versions to be documented in a model version report.

Input controls were developed to ensure configuration management of the inputs to the TSPA model. An MS-Access database was built to store and document input parameter values. Parameter values are passed from the database to the TSPA model as part of the process of running a model simulation. Parameter Entry Forms (PEFs) were developed to provide "roadmaps" back to the controlled sources of the input parameters. 